\title{
Enhanced Performance of non-PGM Catalysts in Air Operated PEM-Fuel Cells
}

Heather M. Barkholtz ${ }^{1,2}$, Lina Chong ${ }^{1}$, Zachary B. Kaiser ${ }^{1}$, Tao Xu' ${ }^{2}$, and Di-Jia Liu ${ }^{1, *}$

1. Chemical Sciences \& Engineering Division, Argonne National Laboratory, 9700 S. Cass Ave, Lemont, IL, 60439, USA

2. Department of Chemistry \& Biochemistry, Northern Illinois University, 1425 W. Lincoln Hwy, DeKalb, IL, 60115, USA

* Corresponding Author, djliu@anl.gov, (phone) + 1-630-252- 4511, (fax) + 1-630-2524176

Abstract

A non-platinum group metal (non-PGM) oxygen reduction catalyst was prepared from "support-free" zeolitic imidazolate framework (ZIF) precursor and tested in the proton exchange membrane fuel cell with air as the cathode feed. The iron nitrogen and carbon composite (Fe-N-C) based catalyst has high specific surface area decorated uniformly with active sites, which redefines the triple phase boundary (TPB) and requires re-optimization of the cathodic membrane electrode fabrication to ensure efficient mass and charge transports to the catalyst surface. This study reports an effort in optimizing catalytic ink formulation for the membrane electrode preparation and its impact to the fuel cell performance under air. Through optimization, the fuel cell areal current density as high as $115.2 \mathrm{~mA} / \mathrm{cm}^{2}$ at $0.8 \mathrm{~V}$ or $147.6 \mathrm{~mA} / \mathrm{cm}^{2}$ at $0.8 \mathrm{~V}_{\mathrm{iR} \text {-free }}$ has been achieved under one bar air. Impacts on fuel cell internal impedance and the water formation are also investigated.

1. Introduction

Proton exchange membrane fuel cells (PEMFCs) are a promising energy conversion technology for future clean power generation. Large-scale 
commercialization of PEMFCs, however, is hindered by the high cost of platinum used as the fuel cell electrode catalyst.[1] Finding inexpensive alternatives to the platinum group metal (PGM) electrode catalysts represents a major focus area for PEMFC material researchers. Recent efforts have afforded significant advancements in non-PGM catalyst syntheses and understanding of their ORR mechanism.[2-14] Among all non-PGM candidates, transition metal and nitrogen doped carbon (TM-N-C) composites prepared from high surface area metal-organic frameworks (MOFs) are particularly promising.[4$6,9,10,12-15]$ Generally, these materials are prepared through pyrolysis of MOFs in the absence of any support; therefore the resulting catalyst has a high density of uniformly distributed active sites. Such catalysts are morphologically distinct from the conventional electrocatalyst materials, which rely on high surface area support materials such as amorphous carbon to achieve high catalytic center dispersion. $[2,7,8$, 16] Typically, support materials are inert with limited or no catalytic activity and do not appreciably contribute to the electrocatalytic process. The inert support also dilutes the active site density and demands more catalyst to deliver a comparable performance. For fuel cells, thin electrode layers are generally preferred due to the constraint of charge and mass transfers, which limit the amount of catalyst can be applied. The MOF-based Fe-N-C catalysts are prepared through thermolysis of the frameworks without the need for a secondary carbon support. By definition, the catalytic centers are evenly decorated throughout the pyrolyzed materials. By judiciously selecting nitrogen-containing ligand and transition metal as MOF's building blocks, one could theoretically produce the number of the active site intrinsically based on the transition metal-N ligation units in 
MOF. This results in greater number of active site within the same volume than the supported catalysts and attributes to a number of reported ORR activities approaching to that of PGM catalysts.[5, 13, 14, 17]

At present, most ORR activities over non-PGM catalysts were tested under oxygen flow. Practical automotive applications require the cathode be supplied with air as the oxidant instead of pure $\mathrm{O}_{2}$. When air is used, a decrease in the fuel cell performance is observed due to the lower content of oxygen ( $20.95 \%$ by volume).[18, 19] For non-PGM catalysts, it is of vital importance to maximize the utilization of available active sites so that they could contribute to the overall catalytic reaction. Electrocatalytic reactions in the fuel cell electrodes occur at the interface between the catalyst, proton conductive ionomer, and gas phase, also known as the "triple-phase boundary" (TPB).[20] The TPB needs to be maximized within the membrane electrode assembly (MEA) to deliver the optimal fuel cell performance. For conventional carbon supported catalyst, TPBs can be modified by altering the catalyst ink formulation involving the change of Nafion ${ }^{\circledR}$ ionomer-to-catalyst ratios. Typically, this ratio is in the range of $1: 1$ to $1.5: 1$. Since MOF derived non-PGM catalyst has a homogenous distribution of the active sites and does not differentiate the catalytic from the support regions, we expect a different ionomer distribution, hence its content in the ink formulation, is needed. Insufficient ionomer will not connect the proton conduction paths between active sites and the membrane. Too much ionomer will block the catalyst pores and prevent gas reactant reaching to the catalytic center. Fully humidified ionomer is an excellent proton conductor, but inadequacies such as poor gas diffusivity 
and low electron conductivity set an upper limit to its loading before the electrode performance is adversely affected.[21, 22] Many reports have found significant dependences of ORR activity on the ionomer-to-catalyst ratio in the electrodes.[13, 14, 23-26]. Changing the oxidant from pure $\mathrm{O}_{2}$ to air may change the characteristics in gas diffusivity and humidity management, therefore requires the re-optimization of electrode fabrication process.

In this work, we report our recent study on improving the MEA fabrication through the catalyst ink optimization for air operated PEMFC singe cell. We found that Nafion ${ }^{\circledR}$ ionomer content has strong influence to the MEA and fuel cell performance. Through the optimization, we have significantly increased the specific current densities at both kinetic and low-voltage regions and achieved high power density for $\mathrm{H}_{2}$-air PEMFC with non-PGM cathodic catalyst.

\section{Methods}

\subsection{Electrocatalyst Synthesis}

Nanoscale ZIF-8 (an imidazolate based MOF) crystals were synthesized via rapid room temperature colloidal chemistry according to previously published procedures.[27, 28] Briefly, 0.02 moles of zinc nitrate hexahydrate was dissolved into $400 \mathrm{~mL}$ of methanol. A second solution was prepared containing 0.2 moles 2 -methylimidazole in $400 \mathrm{~mL}$ of methanol. While stirring, the zinc nitrate hexahydrate solution was poured into the 2-methylimidazole solution, prompting the precipitation of ZIF-8 crystals. After one hour, the precipitate was removed from solution via centrifugation, washed with methanol three times, and dried in a vacuum oven at $40{ }^{\circ} \mathrm{C}$. 
The as-synthesized ZIF-8 $\left(\mathrm{Zn}(\mathrm{mlm})_{2}\right)$ was first combined with tris $(1,10-$

phenanthroline) iron (II) perchlorate (TPI) by ball milling one mole of ZIF-8 with 0.05 molar percent TPI at 500 rpm for one hour. The pink powder comprised of TPI uniformly mixed with ZIF-8 was recovered from the ball mill, placed in a ceramic boat, and in a sealed in a quartz tube furnace for the first thermal activation. The quartz tube was purged with $\mathrm{Ar}$, heated to $1050{ }^{\circ} \mathrm{C}$, and held for 30 minutes to pyrolyze the ZIF-8 material. The resulting black powder was sonicated in $0.5 \mathrm{M} \mathrm{H}_{2} \mathrm{SO}_{4}$ for 30 minutes followed by constant agitation for 18 hours. The sample was removed from the $\mathrm{H}_{2} \mathrm{SO}_{4}$ solution through centrifugation and washed with water until the $\mathrm{pH}$ of the supernatant was neutral. After separation and drying, the sample was activated for the last time in flowing $\mathrm{NH}_{3}$ gas at $950{ }^{\circ} \mathrm{C}$ to yield the electrocatalyst, $\mathrm{Zn}(\mathrm{mlm})_{2} \mathrm{TPIP}$. The BrunauerEmmett-Teller (BET) specific surface area measured at liquid nitrogen temperature was $1100 \mathrm{~m}^{2} \mathrm{~g}^{-1}$

\subsection{MEA Preparation and Testing}

Electrodes were constructed by first preparing catalyst inks followed by painting the inks onto carbon gas diffusion layers. Formulation of cathode catalyst inks involved dispersing $20 \mathrm{mg}$ of $\mathrm{Zn}(\mathrm{mlm})_{2}$ TPIP into varying amounts of 5 wt. \% Nafion ${ }^{\circledR}$ perfluorinated resin solution (ionomer), water, and isopropyl alcohol (IPA) to give desired Nafion ionomer to catalyst ratios. Samples prepared with different Nafion ionomer-to-catalyst dry weight ratios are referred to simply as I:C where I represents the amount of ionomer added relative to the amount of catalyst, $C$. For example, to prepare ink with $l: C=0.85: 1,20 \mathrm{mg}$ of $\mathrm{Zn}(\mathrm{mlm})_{2}$ TPIP was dispersed into $340 \mathrm{mg}$ of 5 
wt.\% Nafion ionomer solution, $340 \mathrm{mg}$ of water, and $680 \mathrm{mg}$ of IPA. This ink was then sonicated for 30 minutes and constantly agitated for 16 hours to give a homogenous ink dispersion. After agitation, the ink was painted directly onto $5 \mathrm{~cm}^{2}$ carbon paper (Sigracet $25 \mathrm{BC}$ ) and dried in a vacuum oven at $40{ }^{\circ} \mathrm{C}$. The gas diffusion electrode (GDE) thus formed has the net catalyst loading ca. $3.5 \mathrm{mg} \mathrm{cm}^{-2}$. Formulation of anode catalyst inks involved dispersing $10 \mathrm{mg}$ of E-TEK 40 wt.\% Pt/C in $80 \mathrm{mg}$ of 5 wt.\% Nafion ${ }^{\circledR}$ ionomer solution, $80 \mathrm{mg}$ of water, and $160 \mathrm{mg}$ of IPA. The resulting catalyst ink was sonicated for 30 minutes then constantly agitated for 16 hours to ensure a homogenous dispersion. Anodes were prepared by painting and drying in a similar way to that of the cathode. Catalyst loading was found to be about $0.3 \mathrm{mg}_{\mathrm{Pt}} \mathrm{cm}^{-2}$.

Membrane electrode assemblies (MEAs) were assembled by hot-pressing the anode and cathode GDEs on the opposite side of a DuPont Nafion ${ }^{\circledR}$ N211 membrane at $120^{\circ} \mathrm{C}$ for 60 seconds under a pressure of $5.4 \times 10^{6} \mathrm{~Pa}$ followed by additional 60 seconds under the pressure of $1.1 \times 10^{7} \mathrm{~Pa}$. Pressure values were calculated assuming that the weight is evenly distributed across the $5 \mathrm{~cm}^{2}$ electrode.

The MEA activity testing was carried out using a Scribner 850 e fuel cell test stand with a single cell assembly con serpentine flow channels and a geometric electrode surface area of $5 \mathrm{~cm}^{2}$. Ultrahigh purity hydrogen was used as the anode feed and zero air was used as the cathode oxidant, both from AirGas. During the test, the cell temperature was held at $80{ }^{\circ} \mathrm{C}$ and a constant flow rate of $0.2 \mathrm{~L} \mathrm{~min}^{-1}$ was maintained for both anode and cathode. Both hydrogen and air were fully humidified at $80^{\circ} \mathrm{C}$ and the backpressure for each electrode was set at 0.5 bar so that the net pressures of $\mathrm{H}_{2}$ 
and air were at one bar, respectively. Polarization curves were recorded by scanning the potential from open circuit voltage (OCV) to $200 \mathrm{mV}$ at 10 seconds per point collecting data at 25 points per decade. Multiple scans were collected with a 5 minute rest at OCV in between scans. The areal current density $I_{A}$ and power density $P_{A}$ were recorded directly from the polarization measurement. Cell impedance $Z_{A}$ was measured by the current interrupt method installed in the fuel cell test stand.

\section{Results and Discussion}

As aforementioned, the non-PGM catalysts derived from MOF/ZIF precursors represent a unique class of materials. Unlike the conventional carbon-supported catalysts, ZIF based catalysts have catalytic sites decorated throughout the internal and external surfaces. There is no clear separation between the catalytically active versus that of inert portions. Since MOF/ZIF derived catalysts are heteroatom doped carbonaceous materials and intrinsically porous, the electron and mass transfers are no longer the concerns. The only challenge is to establish the ion-conductive channels so that as many active sites as possible can be situated near the TPB. At present, the most obvious optimization step is to control the ionomer usage and the application method. Ionomer is a short-chain polymer. Insufficient usage will not provide adequate coverage on the MOF/ZIF catalyst surface which typically has higher surface areas than amorphous carbon catalyst supports. Excessive usage will clog the gas passages to the catalyst micropores which contribute dominantly to the surface areas of these kinds of catalyst. Improving ionomer application involves multiple parameters such as the ionomer solution concentration, the type of solvents, application method to form MEA, 
etc. This investigation, however, limits to only the ink formulation with different $I: C$ ratios.

Five catalyst ink formulations with varying I:Cs were prepared to optimize the catalyst usage and ORR activity of $\mathrm{Zn}(\mathrm{mlm})_{2}$ TPIP using air as the oxidant. The I:C ratios were varied from 1:1 down to $0.5: 1$ and the resulting polarization curves are shown in Figure $1 \mathrm{~A}$. It is immediately obvious that the MEA with cathodic $I: C=0.5: 1$ generated poor ORR activity, presumably resulting from insufficient ionomer coverage thus less TPB over the catalyst surface. Increasing ionomer loading from $I: C=0.5: 1$ to $0.7: 1$ quickly improved the catalyst and MEA performances with $I: C=0.85: 1$ demonstrating the best polarization current in the entire voltage range investigated. Further increasing I:C to 1:1 maintained a relatively high fuel cell performance above $0.8 \mathrm{~V}_{\text {iR-free }}$. However, the current density rapidly deteriorated as the polarization potential reached below 0.7 V. This fast activity decay is presumably due to the excess ionomer accumulation blocking a faction of micropores in the electrode catalyst layer. Such blockage may not have much impact at the kinetic region when the cell current is low. However, it will impede the mass transport at higher cell current when more oxygen is needed as the cell potential decreases.[29, 30]. A closer examination on the cell impedance also found that there is an increase in the internal resistance at $I: C=1: 1$, which will be discussed later. 

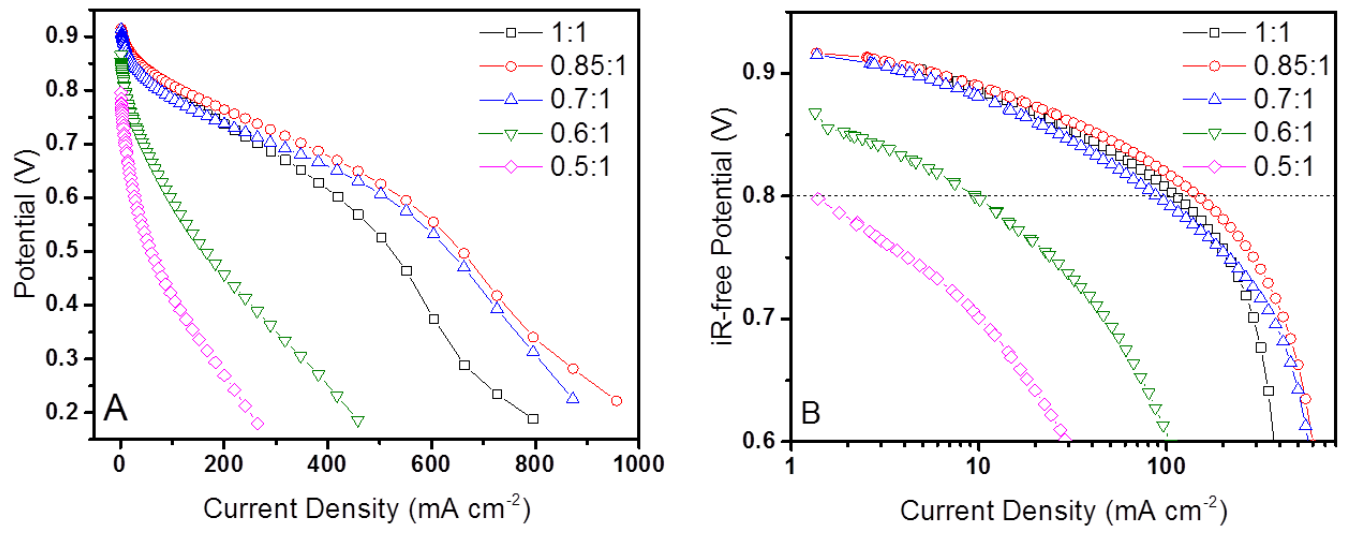

Figure 1. (A) Current-voltage polarization curves for MEAs with different cathodic I:Cs; and (B) Tafel plots derived from the internal resistance corrected cell polarization with different cathodic I:CS. A dashed line was added at $0.8 \mathrm{~V}_{\text {iR-free }}$ to aid in ascertaining the difference between catalyst ink formulations. The legend defines the dry weight ratios of Nafion ${ }^{\circledR}$ ionomer $(I)$ to catalyst $(C)$ as I:C. Conditions: $\mathrm{P}_{\mathrm{H}_{2}}=\mathrm{P}_{\text {Air }}=1$ bar (backpressure $=$ $7.3 \mathrm{psig}$ ) fully humidified; flowrate $\mathrm{H}_{2}=\mathrm{Air}=200 \mathrm{ml} \mathrm{min}^{-1} ; \mathrm{T}=80{ }^{\circ} \mathrm{C} ; \mathrm{N} 211$ membrane; 5 $\mathrm{cm}^{2} \mathrm{MEA}$; cathode catalyst $=3.5 \mathrm{mg} \mathrm{cm}^{-2}$, anode catalyst $=0.3 \mathrm{mg}_{\mathrm{Pt}} \mathrm{cm}^{-2}$.

Selected MEA/fuel cell performance data from the kinetic region to the mass transport limited region are summarized in Table 1. The open circuit voltage (OCV) is the first data point taken after the fuel cell is fully conditioned with steady hydrogen and air flows before the current polarization starts. At the lowest ionomer loading, the OCV was also the lowest, $0.7978 \mathrm{~V}$. As the $I: C$ is increased to $0.6: 1$ and $0.7: 1$, significant improvements in OCV are noted. Further increasing I:C to $0.85: 1$ and $1: 1$ stimulates nominal change. OCV was the highest at $0.9165 \mathrm{~V}$ when $I: C=0.85: 1$, which was very close to $0.9149 \mathrm{~V}$ and $0.9036 \mathrm{~V}$ for $I: C=0.7: 1$ and $I: C=1: 1$, respectively. $O C V$ is governed by voltage losses (or overpotentials) within the fuel cell, even when no current is being generated. These losses are a culmination of small overpotentials from electrode kinetics, reactant crossover, reactant availability, and electronic or ionic resistance.[31] Insufficient ionomer loading, such as $I: C=0.5: 1$ and $0.6: 1$, leads to an electrode with 
high ionic resistance and therefore a greater overpotential and lower OCV. For non-PGM catalyst, the fuel cell specific current density at $0.8 \mathrm{~V}$ has been considered as an important benchmark.[32] We listed in Table 1 the areal specific current densities $\left(I_{A}\right)$ measured at $0.8 \mathrm{~V}_{\mathrm{iR} \text {-free }}$ as well as the measured values without impendence correction $\left(I_{A} @ 0.8 V_{\text {measured }}\right)$ for the MEAs with cathodic $I: C$ values of $0.5: 1,0.6: 1,0.7: 1,0.85: 1$, and 1:1, and plotted $I_{A} @ 0.8 \mathrm{~V}_{\mathrm{iR} \text {-free }}$ in Figure 2 . Figure 2 shows a profound dependence of $I_{A}$ as the function of $I: C$. For example, as $I: C$ is increased from 0.6:1 to 0.7:1, a tenfold increase in specific areal current density at $0.8 \mathrm{~V}_{\mathrm{iR} \text {-free }}$ is observed. Clearly, the proton conductivity to the catalytic active sites is greatly enhanced with a mere $16 \%$ increase in ionomer content at this composition. Further increase of $I: C$ to $0.85: 1$ yielded an impressive specific current densities of $147.6 \mathrm{~mA} \mathrm{~cm}^{-2}$ at $0.8 \mathrm{~V}_{\mathrm{iR} \text {-free }}$ or $115.2 \mathrm{~mA} \mathrm{~cm} \mathrm{~m}^{-2}$ at $0.8 \mathrm{~V}_{\text {measured. }}$ Upon adding more ionomer to reach $\mathrm{l}: C=1: 1$ in the ink mixture caused a decrease in performance by nearly $25 \%$. In addition to $I_{A}$ at $0.8 \mathrm{~V}$, the limiting current $I_{L}$ measured at $0.2 \mathrm{~V}$ followed the same trend as I:C is increased. Their values are also listed in Table 1.

Table 1. Summary of selected fuel cell performance data at different I:Cs.

\begin{tabular}{|l|l|l|l|l|l|l|l|}
\hline$I: C$ & $\begin{array}{l}\text { OCV } \\
(\mathrm{V})\end{array}$ & $\begin{array}{l}I_{A} @ 0.8 \\
V_{\text {measured }} \\
\left(\mathrm{mA} \mathrm{cm}^{-2}\right)\end{array}$ & $\begin{array}{l}I_{A} @ 0.8 \\
V_{\text {iR-free }} \\
\left(\mathrm{mA} \mathrm{cm}^{-2}\right)\end{array}$ & $\begin{array}{l}P_{A} @ 0.6 \\
V_{\text {measured }} \\
\left(\mathrm{mW} \mathrm{cm}^{-2}\right)\end{array}$ & $\begin{array}{l}I_{L} @ 0.2 \\
V_{\text {measured }} \\
\left(\mathrm{Am}^{-2}\right)\end{array}$ & $\begin{array}{l}Z_{A} @ 100 \mathrm{~mA} \\
\mathrm{~cm}^{-2} \\
\left(\mathrm{mOhm} \mathrm{cm}{ }^{2}\right)\end{array}$ & $\begin{array}{l}Z_{A} @ 500 \mathrm{~mA} \\
\mathrm{~cm}^{-2} \\
\left(\mathrm{mOhm} \mathrm{cm}^{2}\right)\end{array}$ \\
\hline $1: 1$ & 0.9036 & 87.2 & 112.4 & 252.6 & 0.7263 & 115.6 & 93.82 \\
\hline $0.85: 1$ & 0.9165 & 115.2 & 147.6 & 325.7 & 0.9565 & 93.25 & 73.48 \\
\hline $0.7: 1$ & 0.9149 & 72.9 & 94.4 & 307.7 & 0.8723 & 94.53 & 70.06 \\
\hline $0.6: 1$ & 0.8679 & 7.4 & 9.396 & 59.66 & 0.5017 & 113.6 & 76.82 \\
\hline
\end{tabular}




\begin{tabular}{|l|l|l|l|l|l|l|l|}
\hline $0.5: 1$ & 0.7978 & ---- & ---- & 16.32 & 0.2638 & 115.6 & --- \\
\hline
\end{tabular}

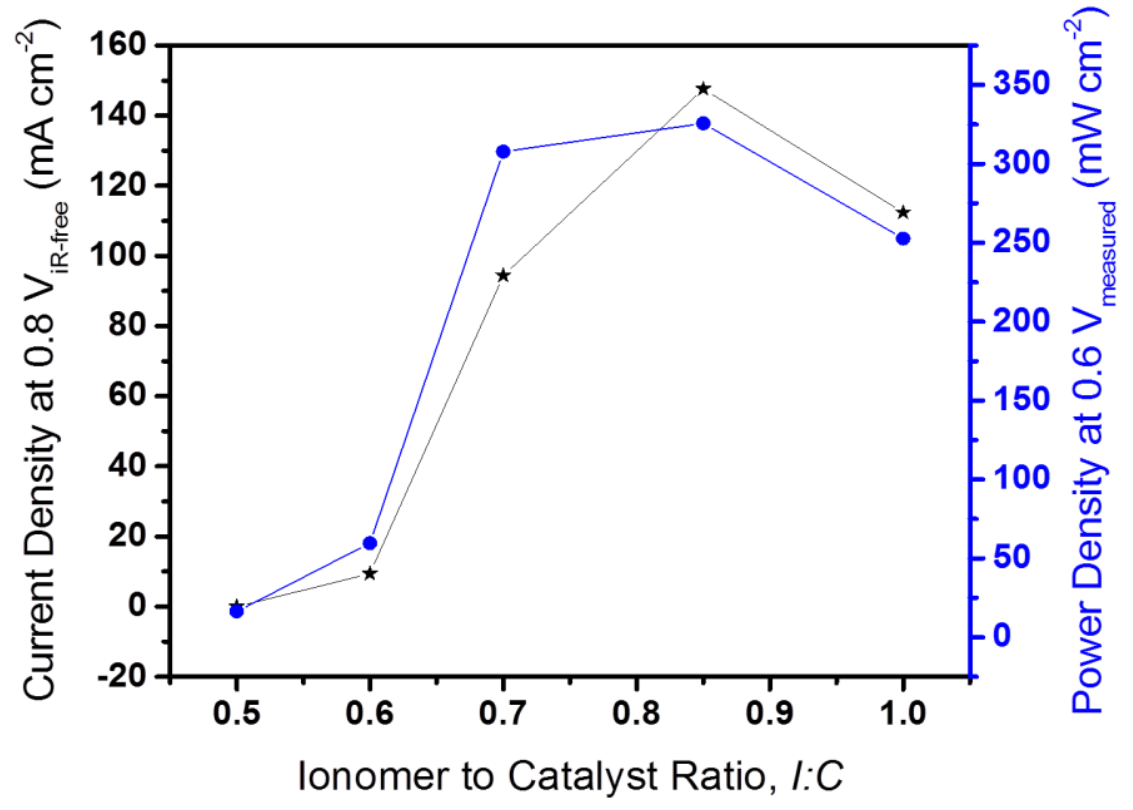

Figure 2. Effect of Nafion ionomer loading on the current densities at $0.8 \mathrm{~V}_{\mathrm{iR} \text {-free }}$ (solid star) and the power density at $0.6 \mathrm{~V}$ (solid circle).

As one would expect, the impact of $I: C$ to fuel cell polarization will also affect its power density distribution. Figure 3A shows the fuel cell power density as a function of polarization current density for the MEAs prepared with different I:Cs. Since hydrogen powered PEMFC provides only meaningful energy conversion efficiency above $0.6 \mathrm{~V}$, the power density values $\left(P_{A}\right)$ at $0.6 \mathrm{~V}$ are compiled in Table 1 and are plotted as a function of $I: C$ in Figure 2. Similar to the assessment of specific current density, the MEA with cathodic $I: C=0.85: 1$ also has the highest power density among all the samples. Different from the sequence of $I_{A}$ at $0.8 V_{\text {iR-free }}$ where MEA with $I: C=0.7: 1$ has a lower value than that with $I: C=1: 1$, the $P_{A}$ reverses the order with the value of $I: C=0.7: 1$ is higher than that with $I: C=1: 1$ at $0.6 \mathrm{~V}$. Changing $I: C$ from $0.85: 1$ to $0.7: 1$ results in only a $5.5 \%$ loss 
of $P_{A}$ at $0.6 \mathrm{~V}$. When $I: C$ value is raised to $1: 1$, the power density falls by $73 \mathrm{~mW} \mathrm{~cm}^{-2}$, or $23 \%$ of its value at $0.85: 1$. This alteration of sequence is simply due to the switch of $I_{A}$ order at $0.7 \mathrm{~V}$ shown in Figure $1 \mathrm{~A}$, resulted from the changes in mass transport and cell impedance characteristics.
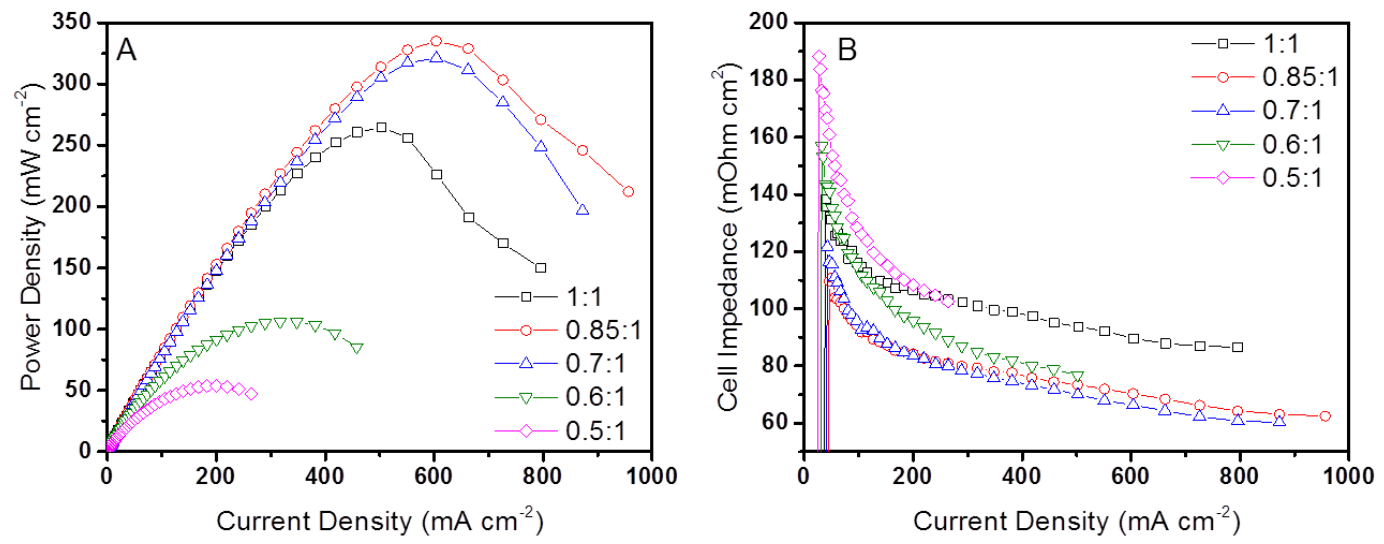

Figure 3. (A) Power density as the function of current density for each I:C and (B) cell impedance curves as the function of current density for each $I: C$. The legend in the graphs defines $I: C$. Conditions: $P_{\mathrm{H}_{2}}=\mathrm{P}_{\text {Air }}=1$ bar (backpressure $=7.3 \mathrm{psig}$ ) fully humidified; flowrate $\mathrm{H}_{2}=$ Air $=200 \mathrm{ml} \mathrm{min}^{-1} ; \mathrm{T}=80{ }^{\circ} \mathrm{C} ; \mathrm{N} 211$ membrane; $5 \mathrm{~cm}^{2}$ MEA; cathode catalyst $=3.5 \mathrm{mg} \mathrm{cm}^{-2}$, anode catalyst $=0.3 \mathrm{mgt}_{\mathrm{Pt}} \mathrm{cm}^{-2}$.

The impact of ionomer loading to the MEA internal resistance during fuel cell operation was also investigated. Figure $3 B$ shows the fuel cell internal impedance, $Z_{A}$, as the function of the polarization current density for MEAs with different I:Cs. Selected $Z_{A}$ values at a lower $\left(100 \mathrm{~mA} \mathrm{~cm}^{-2}\right)$ and higher $\left(500 \mathrm{~mA} \mathrm{~cm}^{-2}\right)$ current density are also summarized in Table 1. Among all the performance parameters discussed in this study, the internal impedance is perhaps the most indicative one in deciphering the influence of the cathodic ink formulation on the electrode structure. Since the Nafion ${ }^{\circledR}$ membrane and anodic ink formation were kept identical through these experiments; the difference in measured internal impedance is therefore associated directly to the variation in 
cathode structure. The internal conductivity is contributed by both proton and electron conductions. The first observation of Figure $3 \mathrm{~B}$ is that when the ionomer content is low, such as when I:C $=0.5: 1$ or $0.6: 1$, the internal impedance becomes high, presumably due to the failure in establishing an effective proton conductive network. The impedance reaches to the lowest values when $I: C=0.7: 1$ and $0.85: 1$, which are coincident with the best fuel cell performance. When I:C is increased to $1: 1$, a significant jump of the internal impedance is observed. Since more ionomer is added under the circumstance, such increase in impedance is likely due to loss of electron instead of proton conductivity. This is an interesting observation for MOF/ZIF derived catalysts. It indicates that a higher content of ionomer may cause segregation of the catalyst particulates by over-coating the surface with excess ion-conducting but electron-insulation polymer, leading to the losses of inter-particle contact and the electron conduction through percolation. Therefore, the degradation of current-voltage polarization of MEA at higher I:C cannot be simply attributed to impeded mass transport, the loss of electron conductivity should also be considered. To our knowledge, this is different from that of amorphous carbon supported catalysts. The second observation of Figure $3 \mathrm{~B}$ is the continuous decrease of cell impedance with the increase of polarization current. This is more pronounced for the MEAs with lower $I: C$ at the current density below $200 \mathrm{~mA} \mathrm{~cm}^{-}$ 2. As aforementioned, MOF/ZIF derived non-PGM catalysts have the unique morphology with the atomic active sites distributed through the entire body, therefore requires generally proper amount of ionomer to reach but not overcast the sites. As fuel cell polarization current increases, the water will be produced at the cathode as the 
product of ORR. Water is an excellent proton conductor which will spill over to the adjacent sites thus expands the TPB. Therefore, both proton conductivity and catalyst utilization could be improved in some degree. The continuous reduction of impedance in Figure $3 \mathrm{~B}$ is accompanied by the extension of current density at lower polarization voltage in Figure $1 \mathrm{~A}$, indicating participation of more active site as water accumulates. Such extension creates a fuel cell polarization curve with shape slightly different from the conventional type. In fact, since the catalyst surface is decorated with high density Fe-N-C moiety which can bind with $\mathrm{H}_{2} \mathrm{O}$ easily, we found that such MEAs tend to have significantly faster "break-in" than the conventional PEMFCs, which will be described below. Increasing proton conductivity and possibly TPB by water alone could not be the solution of overall MEA improvement. For example, in the case of $I: C=0.6: 1$, Figure $3 B$ shows that the cell impedance lowers quickly as the fuel cell is scanned to higher currents. At $500 \mathrm{~mA} \mathrm{~cm}^{-2}$ its impedance had improved to be nearly the same as that of 0.7:1 and 0.85:1 samples. However, such improvements in charge connectivity did not translate directly into enhanced fuel cell performance at $0.8 \mathrm{~V}_{\mathrm{iR} \text {-free }}$ and $0.6 \mathrm{~V}$. The cumulated water, though improved the proton conductivity, only marginally enhanced the catalyst utilization due to still insufficient coverage. To establish an effective ion conducting channels through proper loading of ionomer is still the most important for the electrode fabrication.

For practical applications, the non-PGM catalyst must maintain a stable ORR activity over time. Although this report is not intended for non-PGM catalyst durability study, we did investigate the stability of the membrane electrode during consecutive 
voltage-current polarizations. Typically, Fe-N-C ORR catalysts of high activity deactivate quickly during the fuel cell scanning in pure oxygen.[33-36] To investigate our fuel cell behavior under repeated polarization in air, a MEA with $1: C=0.85: 1$ was prepared and scanned from OCV to $0.2 \mathrm{~V}$ eight consecutive times. The current-voltage polarization curves of these scans are given in Figure $4 \mathrm{~A}$ and corresponding impedance changes as the function of current density are plotted in Figure 4B. Figure 4A shows a consistent improvement of fuel cell polarization during the consecutive scans. The "break-in" was almost completed at the third scan, as is evidenced by the nearly complete overlaps in the low voltage domain. Correspondingly, the cell impedance also converged at the third scan. To closely examine the fuel cell performance, we also plotted fuel cell current densities measured at near the kinetic region $(0.8 \mathrm{~V})$ and mass transport limited region $(0.4 \mathrm{~V})$ in Figure 5 . In the near kinetic region, a small but gradual decay in the specific current density is observed. Meanwhile, the current density near the mass transport limited region approaches a constant value ca. $735 \mathrm{~mA} \mathrm{~cm}^{-2}$ after the third scan and remains basically unchanged in the following scans. Such observation is somewhat difficult to explain based on a single active site model. For the fuel cell with non-PGM catalyst, the "mass-transported limited region" is somewhat ill defined since the limiting current density at low voltage is actually limited by the slower turnover frequency at each active site, instead of the rate the oxidant being supplied. If all the active sites are the same, one would expect the loss of active sites will lead to the reduction of current density at the "mass transport limited region" since every active sites is accountable to perform. In the kinetic region, however, the turn-over rate is 
relatively low and does not require the participation of all the active sites. The fact that the more prominent decay is found first in kinetic region suggests that there may be more than one type of catalytic site. The difference could be from the active site structure or location. The type that contributes to ORR at kinetic region may be more effective in reducing ORR kinetic barrier, but less durable in lifespan. More structural and mechanistic investigations are needed to better understand these changes.
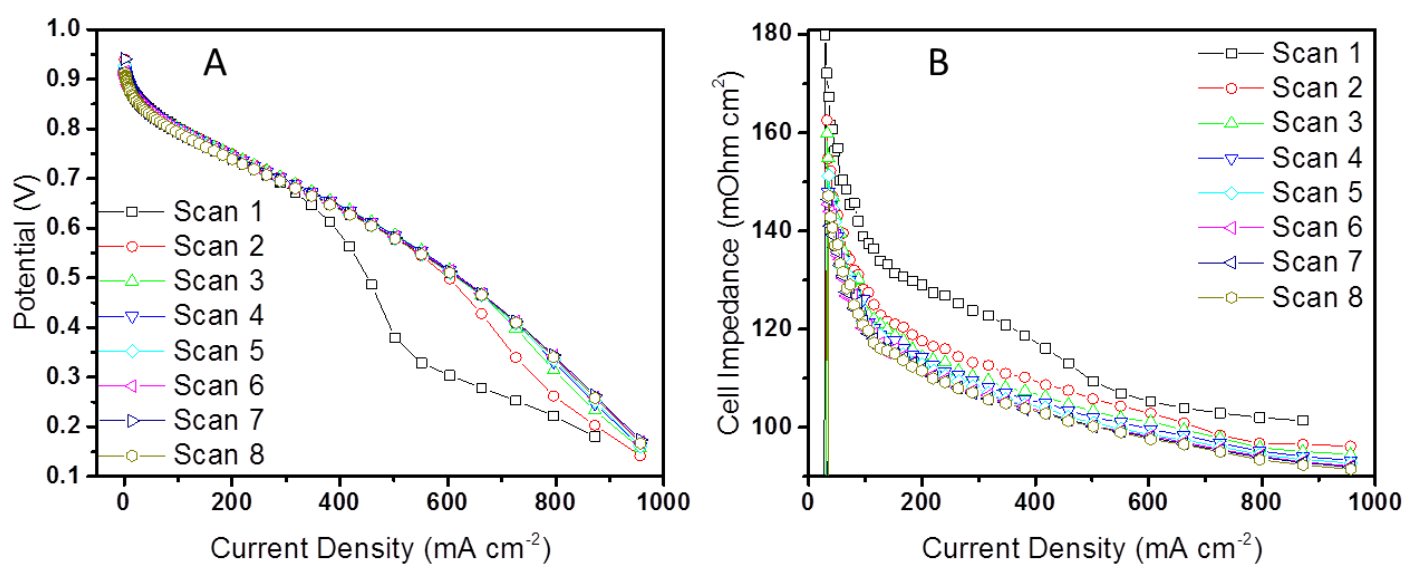

Figure 4. (A) Polarization curves and (B) internal impedances derived from 8 consecutive fuel cell scans. Conditions: $\mathrm{P}_{\mathrm{H}_{2}}=\mathrm{P}_{\text {Air }}=1$ bar (backpressure $=7.3$ psig) fully humidified; flowrate $\mathrm{H}_{2}=$ Air $=200 \mathrm{ml} \mathrm{min}^{-1} ; \mathrm{T}=80^{\circ} \mathrm{C} ; \mathrm{N} 211$ membrane; $5 \mathrm{~cm}^{2} \mathrm{MEA}$; cathode catalyst $=3.5 \mathrm{mg} \mathrm{cm}^{-2}$, anode catalyst $=0.3 \mathrm{mg}_{\mathrm{Pt}} \mathrm{cm}^{-2}$. 


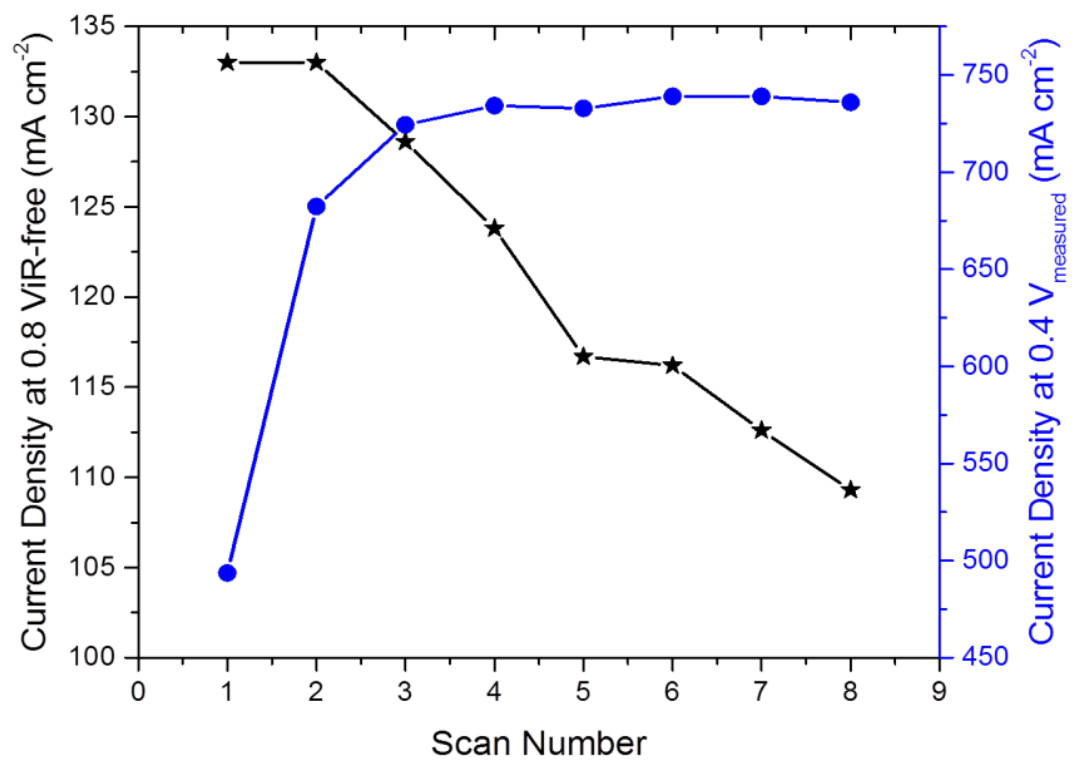

Figure 5 . The change of current density near the kinetic and mass transport regions during 8 consecutive scans.

\section{Conclusion}

An iron, nitrogen incorporated carbon composite (Fe-N-C) was prepared by pyrolysis of tris(1,10-phenanthroline) iron (II) perchlorate (TPI) doped zeolitic methylimidizolate framework. The composite was incorporated as the cathode catalyst in a hydrogen-powered proton exchange membrane fuel cell running air as oxidant. The ORR catalyst offers a unique morphology of uniformly distributed active sites throughout the catalyst body without the distinction between the support and active regions. To optimize the access to these active sites, membrane electrode fabrication process was improved by altering Nafion ${ }^{\circledR}$ ionomer-to-catalyst ratio. Meanwhile, MEA performances were evaluated through the current-voltage polarization. Tafel plot, power density and internal impedance were derived from the polarization 
measurements. We found, for example, the best fuel cell performance can be achieved when ionomer-to-catalyst dry weight ratio was maintained at $0.85: 1$. With the optimized MEA, an excellent specific current density of $115.2 \mathrm{~mA} / \mathrm{cm}^{2}$ at $0.8 \mathrm{~V}$ or 147.6 $\mathrm{mA} \mathrm{cm}{ }^{-2}$ at $0.8 \mathrm{~V}_{\mathrm{iR}-\text {-free }}$ was obtained when the fuel cell was operated under one bar air at $80^{\circ} \mathrm{C}$. Furthermore, a power density of $325.7 \mathrm{~mW} \mathrm{~cm}^{-2}$ at $0.6 \mathrm{~V}$ was achieved under the same operating conditions.

\section{Acknowledgements}

This work was supported by the U.S. Department of Energy, Office of Energy Efficiency and Renewable Energy, Fuel Cell Technologies Office.

\section{References}

[1] Wong WY, Daud WRW, Mohamad AB, Kadhum AAH, Loh KS, Majlan EH. Recent progress in nitrogen-doped carbon and its composites as electrocatalysts for fuel cell applications. Int J Hydrogen Energ. 2013;38:9370-86.

[2] Yu JR, Islam MN, Matsuura T, Tamano M, Hayashi Y, Hori M. Improving the performance of a PEMFC with Ketjenblack EC-600JD carbon black as the material of the microporous layer. Electrochem Solid St. 2005;8:A320-A3.

[3] Gewirth AA, Thorum MS. Electroreduction of Dioxygen for Fuel-Cell Applications: Materials and Challenges. Inorg Chem. 2010;49:3557-66.

[4] Ma SQ, Goenaga GA, Call AV, Liu DJ. Cobalt Imidazolate Framework as Precursor for Oxygen Reduction Reaction Electrocatalysts. Chem-Eur J. 2011;17:2063-7.

[5] Proietti E, Jaouen F, Lefevre M, Larouche N, Tian J, Herranz J, et al. Iron-based cathode catalyst with enhanced power density in polymer electrolyte membrane fuel cells. Nature Communications. 2011;2.

[6] Zhao D, Shui JL, Chen C, Chen XQ, Reprogle BM, Wang DP, et al. Iron imidazolate framework as precursor for electrocatalysts in polymer electrolyte membrane fuel cells. Chem Sci. 2012;3:3200-5.

[7] Inoue H, Hosoya K, Kannari N, Ozaki J. Influence of heat-treatment of Ketjen Black on the oxygen reduction reaction of $\mathrm{Pt} / \mathrm{C}$ catalysts. Journal of Power Sources. 2012;220:173-9.

[8] Lee JS, Park GS, Kim ST, Liu ML, Cho J. A Highly Efficient Electrocatalyst for the Oxygen Reduction Reaction: N-Doped Ketjenblack Incorporated into Fe/Fe3CFunctionalized Melamine Foam. Angew Chem Int Edit. 2013;52:1026-30. 
[9] Tian J, Morozan A, Sougrati MT, Lefèvre M, Chenitz R, Dodelet JP, et al. Optimized Synthesis of Fe/N/C cathode catalysts for PEM fuel cells: A matter of iron-ligand coordination strength. Angewandte Chemie. 2013;125:7005-8.

[10] Zhao D, Shui JL, Grabstanowicz LR, Chen C, Commet SM, Xu T, et al. Highly Efficient Non-Precious Metal Electrocatalysts Prepared from One-Pot Synthesized Zeolitic Imidazolate Frameworks. Advanced Materials. 2014;26:1093-7.

[11] Nam G, Park J, Kim ST, Shin DB, Park N, Kim Y, et al. Metal-Free Ketjenblack Incorporated Nitrogen-Doped Carbon Sheets Derived from Gelatin as Oxygen Reduction Catalysts. Nano Lett. 2014;14:1870-6.

[12] Xia W, Zhu JH, Guo WH, An L, Xia DG, Zou RQ. Well-defined carbon polyhedrons prepared from nano metal-organic frameworks for oxygen reduction. J Mater Chem $A$. 2014;2:11606-13.

[13] Barkholtz HM, Chong LN, Kaiser ZB, Xu T, Liu DJ. Highly Active Non-PGM Catalysts Prepared from Metal Organic Frameworks. Catalysts. 2015;5:955-65.

[14] Shui J, Chen C, Grabstanowicz L, Zhao D, Liu D-J. Highly efficient nonprecious metal catalyst prepared with metal-organic framework in a continuous carbon nanofibrous network. Proceedings of the National Academy of Sciences. 2015;112:10629-34.

[15] Wang X, Zhang H, Lin H, Gupta S, Wang C, Tao Z, et al. Directly converting Fe-doped metal-organic frameworks into highly active and stable Fe-N-C catalysts for oxygen reduction in acid. Nano Energy. 2016;25:110-9.

[16] Nie Y, Li L, Wei Z. Recent advancements in Pt and Pt-free catalysts for oxygen reduction reaction. Chem Soc Rev. 2015;44:2168-201.

[17] Zitolo A, Goellner V, Armel V, Sougrati M-T, Mineva T, Stievano L, et al. Identification of catalytic sites for oxygen reduction in iron- and nitrogen-doped graphene materials. Nat Mater. 2015;14:937-42.

[18] Billings RE, Sanchez M. Solid Polymer Fuel-Cells - an Alternative to Batteries in Electric Vehicles - an Overview. Int J Hydrogen Energ. 1995;20:521-9.

[19] Wang L, Husar A, Zhou TH, Liu HT. A parametric study of PEM fuel cell performances. Int J Hydrogen Energ. 2003;28:1263-72.

[20] O'Hayre R, Barnett DM, Prinz FB. The Triple Phase Boundary: A Mathematical Model and Experimental Investigations for Fuel Cells. Journal of The Electrochemical Society. 2005;152:A439-A44.

[21] Lee SJ, Mukerjee S, McBreen J, Rho YW, Kho YT, Lee TH. Effects of Nafion impregnation on performances of PEMFC electrodes. Electrochimica Acta. 1998;43:3693-701.

[22] Cheng X, Yi B, Han M, Zhang J, Qiao Y, Yu J. Investigation of platinum utilization and morphology in catalyst layer of polymer electrolyte fuel cells. Journal of Power Sources. 1999;79:75-81.

[23] Antolini E, Giorgi L, Pozio A, Passalacqua E. Influence of Nafion loading in the catalyst layer of gas-diffusion electrodes for PEFC. Journal of Power Sources. 1999;77:136-42.

[24] Lefèvre M, Proietti E, Jaouen F, Dodelet J-P. Iron-based catalysts with improved oxygen reduction activity in polymer electrolyte fuel cells. Science. 2009;324:71-4. 
[25] Zhiani M, Gharibi H, Kakaei K. Optimization of Nafion content in Nafion-polyaniline nano-composite modified cathodes for PEMFC application. Int J Hydrogen Energ. 2010;35:9261-8.

[26] Gharibi $H$, Javaheri $M$, Kheirmand M, Mirzaie RA. Optimization of the amount of Nafion in multi-walled carbon nanotube/Nafion composites as Pt supports in gas diffusion electrodes for proton exchange membrane fuel cells. Int J Hydrogen Energ. 2011;36:13325-34.

[27] Cravillon J, Münzer S, Lohmeier S-J, Feldhoff A, Huber K, Wiebcke M. Rapid roomtemperature synthesis and characterization of nanocrystals of a prototypical zeolitic imidazolate framework. Chemistry of Materials. 2009;21:1410-2.

[28] Cravillon J, Nayuk R, Springer S, Feldhoff A, Huber K, Wiebcke M. Controlling Zeolitic Imidazolate Framework Nano- and Microcrystal Formation: Insight into Crystal Growth by Time-Resolved In Situ Static Light Scattering. Chemistry of Materials. 2011;23:213041.

[29] Kong CS, Kim D-Y, Lee H-K, Shul Y-G, Lee T-H. Influence of pore-size distribution of diffusion layer on mass-transport problems of proton exchange membrane fuel cells. Journal of Power Sources. 2002;108:185-91.

[30] Sasikumar G, Ihm JW, Ryu H. Optimum Nafion content in PEM fuel cell electrodes. Electrochim Acta. 2004;50:601-5.

[31] Barbir F. PEM fuel cells: theory and practice: Academic Press; 2013.

[32] http://energy.gov/eere/office-energy-efficiency-renewable-energy. Accessed 0211-2016.

[33] Borup R, Meyers J, Pivovar B, Kim YS, Mukundan R, Garland N, et al. Scientific aspects of polymer electrolyte fuel cell durability and degradation. Chemical reviews. 2007;107:3904-51.

[34] Meng H, Larouche N, Lefèvre M, Jaouen F, Stansfield B, Dodelet J-P. Iron porphyrinbased cathode catalysts for polymer electrolyte membrane fuel cells: Effect of NH3 and Ar mixtures as pyrolysis gases on catalytic activity and stability. Electrochimica Acta. 2010;55:6450-61.

[35] Li X, Liu G, Popov BN. Activity and stability of non-precious metal catalysts for oxygen reduction in acid and alkaline electrolytes. Journal of Power Sources.

2010;195:6373-8.

[36] Jaouen F, Proietti E, Lefevre M, Chenitz R, Dodelet J-P, Wu G, et al. Recent advances in non-precious metal catalysis for oxygen-reduction reaction in polymer electrolyte fuel cells. Energy \& Environmental Science. 2011;4:114-30. 